\title{
A comparative analysis of cohesion in academic and newspaper texts
}

\author{
Sarah Ambiyo
}

\section{Introduction}

\subsection{Background to the Study Problem}

This article presents findings on a comparative analysis of cohesion in academic and newspaper texts on road traffic accidents. Cohesive devices are the surface structure features that link different parts of a text and make it flow logically. They are the necessary reins that hold the clauses of a text together. Coherence, on the other hand, is the property by which the textual world is relevant, accessible and acceptable to the reader. Thus the text hangs together and makes meaning, as it is easily read and understood.

The research problem stems from text linguistics and uses a functional approach to study stretches of text. Text linguistics emphasizes the use of naturally occurring language data in its context and explores the text as the primary object of inquiry. This study thus fills a gap in knowledge as most studies existing in East Africa utilize a formal approach and mainly concentrate on language structures below the sentence e.g. Njoroge (1996). Text in this study refers to written forms drawn from newspaper reports and academic writing on road traffic accidents.

\subsection{Statement of the Problem}

A comparative analysis is carried out in this study on cohesion in road traffic accident reports drawn from newspaper articles and excerpts of written academic texts. The analysis in this study is guided by Halliday and Hasan's (1976) cohesive categories, which are later reclassified according to whether they play a cohesive or coherent role to the development of the text.

\subsection{Objectives of the Study}

This study seeks to achieve the following objectives:

1. To identify and describe the type of cohesive features used in newspaper reportage and academic texts on road traffic accidents.

2. To explain the use of static and dynamic cohesive devices in these two text categories.

3. To compare the coherence of the two text categories.

\subsection{Scope and Limitations of the Study}

The study was limited to newspaper reportage and academic writing on road traffic accidents. In addition, the study utilized extracts from the discussion sections of three academic reports, to provide data for this category. Analysing a whole lengthy report tend to result in omission of significant details. 


\subsection{Rationale for the Study}

This study fills a gap in knowledge as there has been a tendency for most linguistic studies to emphasize on a formal approach while dwelling on theoretical linguistic levels lower than the sentence e.g. Njoroge (1996). In this article, however, a functional approach is adopted to provide some insight on issues regarding suprasentential structures. Thus, a detailed analysis of the different roles played by static and dynamic cohesive devices reveals which type contributes significantly to coherence of texts.

Road traffic accidents are a social, health and economic national problem in Kenya today as they frequently occur and involve large numbers of people. For example, a record 3000 people were reported died in 1995 (Kenya Times $1^{\text {st }}$ January 1996). There is therefore a practical need for knowledge on such accidents from all possible sectors e.g. medicine, geography, and even the road safety council. It is believed that this study with a linguistic perspective, albeit a theoretical one, contributes some insight into the linguistic strategies adopted by both the news media and scholars in reporting on them.

\section{Research Methodology}

The present study uses three texts from the newspaper text category and three from the academic category. This is as in other comparison studies of text analysis, like Bazerman (1981) and Lovejoy (1991) that use three text samples each.

To provide a variety of sample sources, an accident reported on $9^{\text {th }}$ April 1995 in the three daily newspapers in Kenya at the time namely: the Daily Nation, the East African Standard, and the Kenya Times was used. The month of April had the highest number of road traffic accidents that year, and this report was the lengthiest, having more than three hundred words in all the three daily newspapers.

The academic text category also had three texts excerpted from: Agoki (1988), Baerwald (1973) and Jacobs Fouracre (1977), all having more than 300 words.

The discussion section of these texts had no diagrams or listed points that would distort their cohesive flow. Each text category had 56 sentences.

Before identification of cohesive features, the individual sentences of every text extract were rewritten. The cohesive devices identified were then listed and grouped into reference, conjunction, lexical cohesion and substitution /ellipsis. A further analysis involved recategorising these cohesive features into those that achieve staticness and those that achieve dynamism. Static cohesive devices connect stretches of text of text and are responsible for cohesion. They include: the definite article, pronounce reference, substitution /ellipsis, lexical repetition, and synonymy. Dynamic ones, on the other hand, advance the logic of the discussion by specifying how a writer manipulates an internal representation. They are responsible for the coherence of the text. They include comparative and demonstrative reference, conjunctions and lexical superordinates. Their frequencies of occurrence in the text samples were calculated, enabling comparison of coherence of the two text categories on road traffic accidents. 


\section{Research Findings}

The findings of the study are presented below:

a. Both newspaper reportage and academic writing use references, conjunctions, substitution /ellipsis and lexical cohesion to bring about connections in their texts. However, while substitution /ellipsis are rarely used, lexical cohesion is very common.

b. Dynamic cohesive features that introduce new relationships in the text, developing it, and rendering its easy reading are sparsely employed. Static ones, on the other hand, are very abundant.

c. The academic text category employs more of lexical repetitions, demonstrative reference and conjunctions because:

1. It is a relatively formal discursive genre, which has to persuade the reader to follow its opinion by clearly stating its views with supportive evidence.

2. It has to convince the reader by carefully presenting its argument logically and forcefully.

3. It defines a narrow topic of study and often reiterates technical terminology of the discipline.

4. It may need to compare two or more issues if the comparison will reinforce the argument.

5. It targets a specific audience of members of the discipline who will easily comprehend the technical language employed in the text.

6. It does not narrate things that happen to people like the reportages, but discusses issues hence demonstrative reference is used as opposed to pronoun reference.

This text category therefore employs more dynamic cohesive features and is much easier to read and follow the argument.

The newspaper reportage text category on the other hand uses more lexical synonyms and superordinates, pronoun and definite references and nominal ellipsis since:

1. Its purpose is to convey current news to the public, so it has to ensure that as much information is contained in a news edition as possible.

2. It has to ensure that no profitable space is wasted.

3. It has to be attractive and stay ahead of the competition, and thus avoids monotonous repetitions.

4. It narrates things that happen to people and so constantly makes references to them as it creates some organization in the text.

5. It has to cater for people of different backgrounds and must therefore use generalized language.

Lastly, the academic text category in this study appears to have better development than the reportage category, which has comparatively fewer dynamic cohesive ties. Ranking coherence of the two text categories on a cline using static and dynamic cohesive devices as the yardstick, coherence of academic texts is ranked above that of 
newspaper reportage texts. This difference does not however render reportage texts as incoherent.

\section{Implications of the Findings.}

The findings of this study have a number of implications;

a. Coherence may be helpful to teachers as various disciplines create cohesion in different ways. Teachers of various disciplines may find them useful in guiding their students on how to develop texts, make them flow well and be easily readable.

b. Writers of newspaper reports on road traffic accidents may need to go further than merely describing the accident and inject some argument that could strongly bring out the need for safe road usage by all.

\section{Conclusion.}

Understanding how the concept of coherence is fleshed out by various genres of texts is crucial in comprehension and information packaging. The academic genre differs from the journalistic genre in creating the semblance of coherence.

\section{References}

Agoki, S.G. (1988). 'Characteristics of Road Traffic Accidents in Kenya', unpublished Ph.D. thesis, University of Nairobi.

Baerwald, J.E. (1973). 'Wheels of Progress?' in Rose, J. (Ed) Motor Transport Pollution and the Environment, Gordon and Breach Science Publishers.

Daily Nation, (9-4-95), '12 Perish as Bus Goes up in Flames, Nairobi, Nation Group.

East African Standard, (9-4-95),'12 Die in Horror Crash', the Standard Limited, Nairobi.

Halliday, M.A.K. and R. Hasan, (1976). Cohesion in English London, Longman.

Jacobs, G.D. and P.R. Fouracre, (1977). 'Further Research on Road Traffic Accidents in Developing countries' in Transport and Road Research Laboratory, Crowthorn, Birkshire.

Kenya Times, (1-1-96), 'Last Years' Death Toll', Nairobi, Kenya Times Media trust.

Kenya Times, (9-5-95), 'Horror Crash Leaves 12 Dead as 5 others Perish on NairobiMombasa Highway', Nairobi, Kenya Times Media Trust.

Lovejoy, B.K. (1991). 'Cohesion and Information Strategies in Academic Writing: Analysis of Passages in Three Disciplines', in Linguistics and Education.

Njoroge, M.C. (1996). 'Morphosyntactic Structures in the Written English of First Year Undergraduate Students in Kenya', Unpublished MA Thesis, Kenyatta University. 